\title{
Ending Aging in Super Glassy Polymer Membranes**
}

\author{
Cher Hon Lau, Phuc Tien Nguyen, Matthew R. Hill,* Aaron W. Thornton, Kristina Konstas, \\ Cara M. Doherty, Roger J. Mulder, Laure Bourgeois, Amelia C. Y. Liu, David J. Sprouster, \\ James P. Sullivan, Timothy J. Bastow, Anita J. Hill, Douglas L. Gin, and Richard D. Noble*
}

\begin{abstract}
Aging in super glassy polymers such as poly(trimethylsilylpropyne) (PTMSP), poly(4-methyl-2-pentyne) $(P M P)$, and polymers with intrinsic microporosity (PIM-1) reduces gas permeabilities and limits their application as gasseparation membranes. While super glassy polymers are initially very porous, and ultra-permeable, they quickly pack into a denser phase becoming less porous and permeable. This age-old problem has been solved by adding an ultraporous additive that maintains the low density, porous, initial stage of super glassy polymers through absorbing a portion of the polymer chains within its pores thereby holding the chains in their open position. This result is the first time that aging in super glassy polymers is inhibited whilst maintaining enhanced $\mathrm{CO}_{2}$ permeability for one year and improving $\mathrm{CO}_{2} / \mathrm{N}_{2}$ selectivity. This approach could allow super glassy polymers to be revisited for commercial application in gas separations.
\end{abstract}

$S_{\text {eparation processes are some of the highest energy }}$ consumers on the planet, underlining the importance of finding more efficient materials and processes to employ in this field. ${ }^{[1]}$ With regard to gas separation, examples include natural gas purification, air enrichment, hydrogen recovery, and post combustion carbon capture from flue gas. ${ }^{[2]}$ Polymer membranes are attractive candidates for such separations because of their processability and ability to operate at scale. ${ }^{[3]}$ Gases traverse the polymer at different rates, through either solution- or diffusion- (activation, surface, and Knudsen diffusion mechanisms ${ }^{[4]}$ ) dominated processes, which leads to the separation of a mixture. Key performance attributes in polymer gas membranes include the permeability (speed of gas transport) and selectivity (speed of one gas relative to another). It has been shown by Robeson ${ }^{[5]}$ and explained by Freeman ${ }^{[6]}$ that the optimization of permeability comes at the expense of selectivity. Known as the "upper bound", this trade-off is described by a log-log plot of permeability versus selectivity for all known polymer membranes.

Naturally, all glassy polymers, particularly porous versions, age physically. As polymer chains relax towards an unachievable thermodynamic equilibrium, free volume content is reduced and chain mobility is restricted. ${ }^{[7]}$ Polymer aging is most prevalent in polymers with poor chain packing density that have exceptionally high fractional free volume (FFV) content. Over time, the packing density increases, and the permeability drops dramatically. ${ }^{[8]}$ Examples of such materials include rigid, kinked, shape-persistent ladder polymers, ${ }^{[9]}$ and substituted polyacetylenes. ${ }^{[10,11]}$

The tantalizing initial performance of polyacetylenes coupled with their physical aging challenges led to a large body of research aimed towards freezing the initial high fractional free volume state in place. One approach included the use of additives, such as nanoparticles, ${ }^{[12]}$ polymer blends, ${ }^{[13]}$ or microporous organic fillers (or polymers) ${ }^{[14]}$ to prop open and increase transport pathways. Other approaches were aimed at rigidifying the initial polymer structure in place, using surface plasma treatment, ${ }^{[15]}$ crosslinking, ${ }^{[16]}$ or co-polymerization. ${ }^{[17]}$ Additive approaches did not sufficiently stabilize the FFV to stop aging, whereas crosslinking was successful at stopping aging but with a major loss in permeability. The inability to stop aging in polyacetylenes provided a research impetus for new rigid, porous materials like PIMs. ${ }^{[9,18]}$ PIMs are made from rigid components with internal flexibility, and most importantly, points of contortion. ${ }^{[19]}$ Similar efforts utilized to stop aging in polyacetylenes have been used to little effect in attempts to inhibit aging in polymers with intrinsic microporosity (PIMs). ${ }^{[16,20]}$ As a result
[*] Dr. C. H. Lau, Dr. M. R. Hill, Dr. A. W. Thornton, Dr. K. Konstas, Dr. C. M. Doherty, Dr. R. J. Mulder, Dr. T. J. Bastow, Dr. A. J. Hill CSIRO Division of Materials Science and Engineering Private Bag 33, Clayton South MDC, VIC 3169 (Australia) E-mail: Matthew.Hill@csiro.au

Dr. P. T. Nguyen, Prof. D. L. Gin, Prof. R. D. Noble Department of Chemical and Biological Engineering University of Colorado

Boulder, CO 80309 (USA)

E-mail: nobler@colorado.edu

Dr. L. Bourgeois

Monash Centre for Electron Microscopy, Department of Materials Engineering, Monash University, Clayton Victoria 3800 (Australia) Dr. A. C. Y. Liu

Monash Centre for Electron Microscopy, School of Physics Monash University, Clayton Victoria 3800 (Australia)
Dr. D. J. Sprouster, Prof. J. P. Sullivan

ARC Centre for Antimatter-Matter Studies, Research School of Physics and Engineering, Australian National University Canberra, ACT 0200 (Australia)

[**] M.R.H. thanks the Victorian government for provision of the Victoria Fellowship. Parts of this work were supported by the Science and Industry Endowment Fund (SIEF). M.R.H., C.M.D., T.J.B., A.W.T., and A.J.H. acknowledge the support of the CSIRO Office of the Chief Executive Science Team. P.T.N., R.D.N., and D.L.G. thank the Advanced Research Projects Agency-Energy (grant: DE-AR0000098) and Total Petrochemicals for financial support of the portion of the work performed at CU Boulder. D.J.S. and J.P.S. would also like to acknowledge the funding received from the ARC Centres of Excellence program.

Dupporting information for this article is available on the WWW under http://dx.doi.org/10.1002/anie.201402234. 
of physical aging, commercial applications of these super glassy polymers remain limited. Thus, more-stable, lowpermeability membrane materials are employed, and these require much larger membrane modules (more surface area) and gas volumes of $\mathrm{CO}_{2}$ separation from flue-gas streams drives the quest for high permeability membranes for this application. ${ }^{[21]}$

Herein, we address the problem of polymer aging by showing that the addition of a very specific microporous microparticle-porous aromatic framework (PAF; Figure 1 A) forms an interwoven nanocomposite with super glassy polymers, freezing the structure and hence stopping the aging process (Figure $1 \mathrm{~B}$ ) whilst increasing the gas permeability and selectivity. For PAF-1, tetrakis(4-bromophenyl)methane (Figure 1 A(1)) is self-condensed by a Yamamoto coupling reaction to form a carbon-based microporous array (Figure 1 A(2)). ${ }^{[22]}$ Brunauer-Emmett-Teller (BET) surface areas in PAFs are as high as $5200 \mathrm{~m}^{2} \mathrm{~g}^{-1}$, which with functionalization can lead to ultrahigh affinities for adsorption of carbon dioxide and other gases. ${ }^{[23]}$ The regular nanopores of around $1.2 \mathrm{~nm}$ diameter (Figure S9 in the Supporting Information) are attractive for the intercalation of polyacetylene side-chain or bulky chemical moieties in PIMs, thereby freezing the as-cast lower-density polymer structure in place and tuning the aging process. This to deliver the required capacity. Nonetheless, the sheer scale

mechanism is distinct from the enhanced permeability effect of non-porous nanoparticle ${ }^{[24]}$ and porous nanoparticle ${ }^{[25]}$ additions to super glassy polymers that prop open the polymer chains at the nanoparticle/polymer boundary but do not prevent aging. Super glassy polymer/PAF-1 membranes were cast by slow solvent evaporation following extended pre-stirring of the mixture. Electron micrographs of $50 \mathrm{~nm}$ thin PTMSP/PAF-1 films in Figure $1 \mathrm{C}$ and D show the fine intercalation of PTMSP within PAF-1 particles. The location of bulky side chains and chemical moieties within PAF1 particles is pinpointed using complimentary solid-state ${ }^{13} \mathrm{C}$ NMR spectroscopy and positron annihilation lifetime spectroscopy (PALS) techniques. Anti-aging properties of the super glassy polymer/PAF-1 membranes were verified using a range of repeated and complementary measurements performed independently in two laboratories. The addition of PAF-1 into super glassy polymers increases the $\mathrm{CO}_{2}$ permeability drastically, from $25 \%$ in PTMSP to as much as $320 \%$ in PIM-1 (Figure 2). These results, whilst in themselves notable, can be readily explained as a function of the increased pore fraction PAF-1 introduces to the system (Tables S1 and S2). In line with this result, $\mathrm{N}_{2}$ permeability also increases, in some cases at the expense of selectivity (Figure S4).

PAF-1 addition to super glassy polymers largely stops aging; there has been no significant decrease (less than $7 \%$ ) in $\mathrm{CO}_{2}$ permeability over time with over 240 days of data at hand. Over time, $\mathrm{N}_{2}$ permeability
(A)

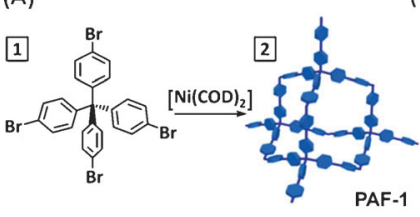

(B)

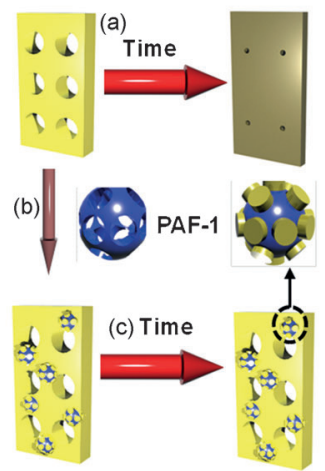

(C)
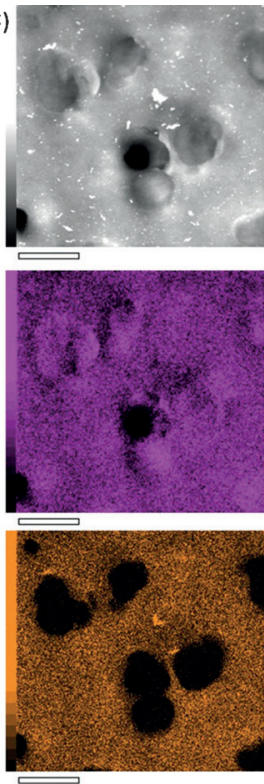
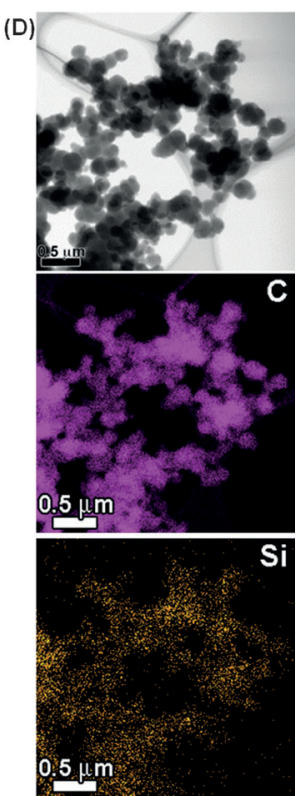

Figure 1. A) Synthesis of PAF-1 particles. B) Super glassy polymer/PAF-1 intermixing. Typically a) PTMSP, PMP, and PIM-1 densify to give a non-permeable conformation, b) but with the addition of PAF-1, c) the original permeable structure is maintained. C) TEM and EDX mapping (purple: carbon map, orange: silicon map) of $50 \mathrm{~nm}$ thin PTMSP/PAF-1 film show that PAF-1 particles (outlined by black circles in the $\mathrm{Si}$ map) are surrounded by $\mathrm{Si}$, indicating the fine dispersion of PAF-1 within the PTMSP matrix. Scale bar is $300 \mathrm{~nm}$. D) TEM and energy dispersive X-ray spectroscopy (EDX) analysis of pre-treated PAF-1 particles that were immersed in PTMSP solution show that $\mathrm{Si}$ is well-intercalated within the PAF-1 particles. Scale bar is $0.5 \mu \mathrm{m}$. These particles were washed thoroughly with chloroform prior to imaging. The structural formula of PTMSP and PIM-1 are shown in Figure 3, PMP structural formula can be found in the Supporting Information. decreased (Figure S4) in some cases improving the selectivity for $\mathrm{CO}_{2} / \mathrm{N}_{2}$. The nanoporous metal-organic framework (MOF), ZIF-8, was included as a further test material. PTMSP/ZIF8 nanocomposites exhibit aging performance almost identical to the native PTMSP control (Figure S4) and similar to reported aging results for porous additives. ${ }^{[2]}$ This result indicates that the anti-aging mechanism is particular to PAF-1: super glassy polymer chain intercalation within the PAF and local interaction of PAF with the methyl groups that freezes free volume; and is probed by ${ }^{13} \mathrm{C}$ solid-state NMR and PALS.

Carbon spin-lattice relaxation times $\left(\mathrm{T}_{1}\right)$ measured by ${ }^{13} \mathrm{C}$ NMR spectroscopy indicate the relative mobility of carbon sites in super glassy polymers, while PALS gives information on the size and number of pores within the material. (Figure 3) Decreases in $\mathrm{T}_{1}$ are indicative of additional local free volume for the particular moiety; increases in $T_{1}$ are indicative of an increase in local packing density. ${ }^{[27]} \mathrm{NMR}$ experiments reveal two clear effects. First, as-cast super glassy polymers and aged super glassy polymer/PAF1 bear a remarkable resemblance, whereas as-cast polymer films are significantly different to aged films. Second, the interaction mechanism between super glassy polymers and PAF-1. Taken together, the results show that PAF-1 freezes the initial polymer chain packing in place. 


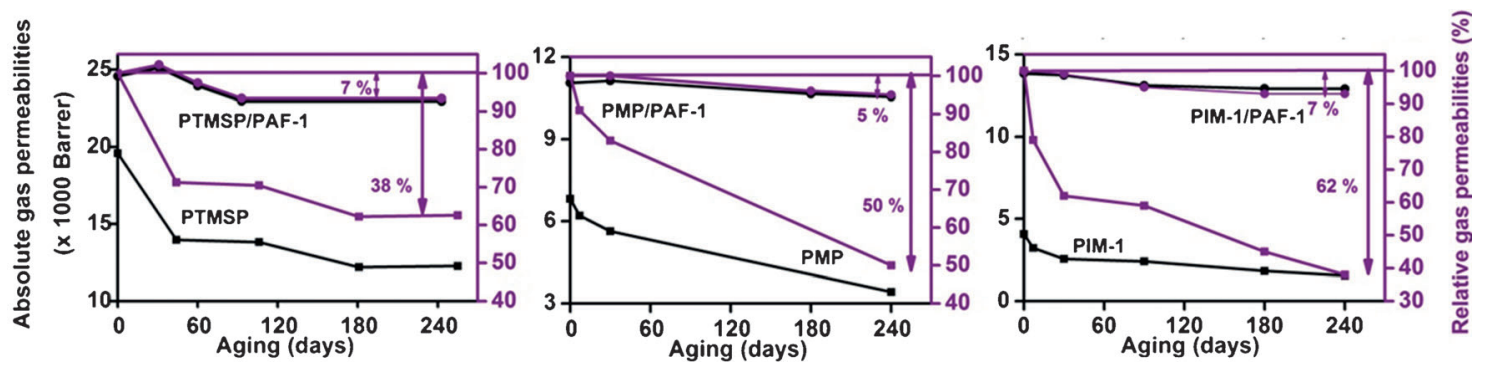

Figure 2. Absolute (black) and relative (purple) $\mathrm{CO}_{2}$ permeabilities of PTMSP-,PMP-, and PIM-1-based membranes; pristine polymers (squares), and polymer/PAF-1 (circles) membranes. Lines are drawn to guide the eye. The deviation of these permeability measurements is within $\pm 10 \%$. Purple arrows show the aging degree in these membranes. Super glassy polymer/PAF-1 membranes do not age over time, while super glassy polymer membranes suffer from aging as $\mathrm{CO}_{2}$ permeability is reduced by $38-62 \% . \mathrm{N}_{2}$ permeabilities are shown in Figure $\mathrm{S} 4$.
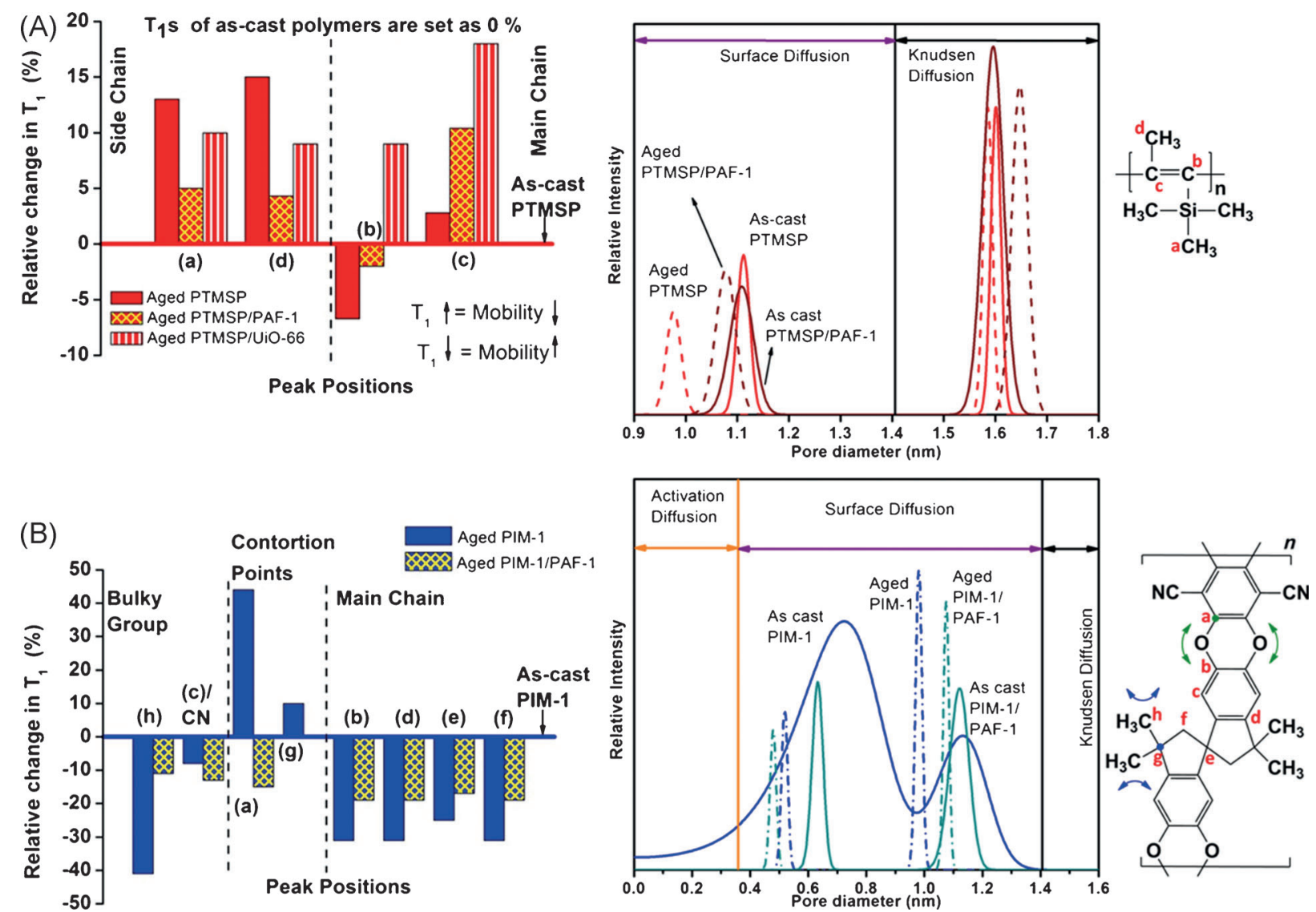

Figure 3. Results from solid-state ${ }^{13} \mathrm{C}$ NMR (left) and PALS (right) spectra of A) PTMSP-, and B) PIM-1-based membranes. Structural formula of PTMSP and PIM-1 are also shown. Relative changes in $T_{1}$ values of PTMSP- and PIM-1-based membranes with respect to as-cast respective polymers (set as $0 \%$ ). Carbon atoms (b), (d), (e), and (f) of PIM-1 are always mobile as they are located within internally flexible components. NMR signals for atom (c) and CN in PIM-1 overlap. UiO-66 is a Zr-based metal-organic framework, and is used to highlight the unique ability of PAF-1 to tether polymer chains within its pores. PMP and PMP/PAF-1 NMR and PALS spectra are in the Supporting Information.

In PTMSP, $\mathrm{T}_{1}$ for main-chain carbon atoms (labeled as $\mathrm{b}$, c) decrease by $2 \%$ and increase by $12 \%$ (relative to as-cast PTMSP), respectively, on aging, whereas the side-chain carbon atoms tell a different story. The pendant methyl group (d) and most crucially, the trimethylsilyl group (a) appear to be essentially unchanged with aging. The pendant trimethylsilyl groups, key to propping main chains open and delivering free volume, dominate interchain interaction and chain packing, a key driver of free volume and hence permeability. ${ }^{[28]}$ The overall mechanism revealed in these data is that the PTMSP is tethered by the inclusion of pendant methyl groups within PAF-1 pores, affecting the freedom of main-chain segments, and leaving trimethylsilyl groups unchanged (see Figure 1B which shows schematically how PTMSP chains are tethered within the pores of PAF-1). Compared to $\mathrm{T}_{1}$ values of PTMSP/MOF nanocomposites, it is evident that the tethering mechanism is not valid for all porous particles. Essentially, this mechanism with PAF-1 is 
a very local form of phase separation, with similar chemical groups being attracted to one another, in this case the saturated aliphatic components of PTMSP with the aromatic rings of PAF-1. ${ }^{[29]}$

Beamline PALS shows pores of approximately $1.2 \mathrm{~nm}$ diameter in PTMSP films shrink and lessen in concentration with aging, accounting for the lowered gas permeability over time. Other pores are largely unchanged. Notably, in PTMSP/ PAF-1 membranes, these $1.2 \mathrm{~nm}$ pores are slightly reduced in size, thus contributing to the extremely slow aging effect observed. Bulk positron annihilation spectroscopy reveals that this effect is largely confined to the surface, with pores in this size regime remaining largely unchanged with time (Table S1). Inter-PAF-1 particle porosity $(4.79 \mathrm{~nm})$ is completely removed in the nanocomposites, indicative of intimate mixing. Accounting for the $10 \mathrm{wt} \%$ PAF-1 loading, the intrinsic PAF-1 pores $(1.2 \mathrm{~nm})$ and the inter-chain PTMSP pores $(1.2 \mathrm{~nm})$ are present in the composite in an increased number if compared to a non-interacting mixture, indicative of more PTMSP inter-chain free volume, which is commensurate with the increased permeability observed. PMP/PAF1 films confirm these trends (Figure S11 and S19).

The aging mechanism varies slightly for PIM-1/PAF1 films. PAF-1 addition does not inhibit pore shrinkage, and this result is proportionate with $\mathrm{N}_{2}$ permeability loss over time. The pores shrink to approximately $0.6 \mathrm{~nm}$, favorable for $\mathrm{CO}_{2}$ sorption, hence enhancing $\mathrm{CO}_{2} / \mathrm{N}_{2}$ selectivity over time. (Figure 4) For PIM-1/PAF-1 nanocomposites, the largest pore size distribution observed is wide enough to facilitate $\mathrm{CO}_{2}$ and $\mathrm{N}_{2}$ activated diffusion only. Figure S12 and S13 show that PAF-1 maintains enhanced $\mathrm{CO}_{2}$ sorption in PIM-1 over time. Carbon atoms (a) and (g) (see Figure 3) are crucial for the bending and flexing of rigid components in PIM- $1^{[19]}$ and are sensitive to the motion of the carbon atom (h) in the dimethyl group and the cyano group. PAF-1 drastically reduces the mobility of carbon atom $(\mathrm{h})$, thus freezing carbon atom $(\mathrm{g})$ that consequently inhibited PIM-1 flexing. Meanwhile carbon atom (a) that is, the dibenzodioxane component gains flexibility. The NMR spectroscopy results pinpoint the location of the tethered site-the dimethyl group within the pore periphery of PAF-1 particles-and validate the hypothesis of similar chemical groups being attracted to one another, in this case the saturated components (dimethyl) of PIM1 and the aromatic PAF-1.

To further elucidate the relationship between pore size distribution and gas transport during aging, we adopt a unified transport model (see Supporting Information) combining mechanisms of size sieving activated diffusion, pore sizedependent solubility (S), and Knudsen diffusion. Using the actual pore size distributions for PIM-1 and PIM-1/PAF1 nanocomposites as an input for the model, the permeability and selectivity trends over time for these materials were predicted and are shown in Figure 4. Higher $\mathrm{CO}_{2} / \mathrm{N}_{2}$ selectivity is ascribed to a reduced small pore size distribution in aged PIM-1/PAF-1 nanocomposites. Additionally, this reduced pore size distribution of $0.47 \mathrm{~nm}$ is also closer to the optimal pore size of $0.42 \mathrm{~nm}$ for $\mathrm{CO}_{2}$ solubility, ${ }^{[4]}$ hence achieving higher permeability; and the large pore size $(1.2 \mathrm{~nm})$ for PIM-1/PAF-1 is maintained during aging. There-

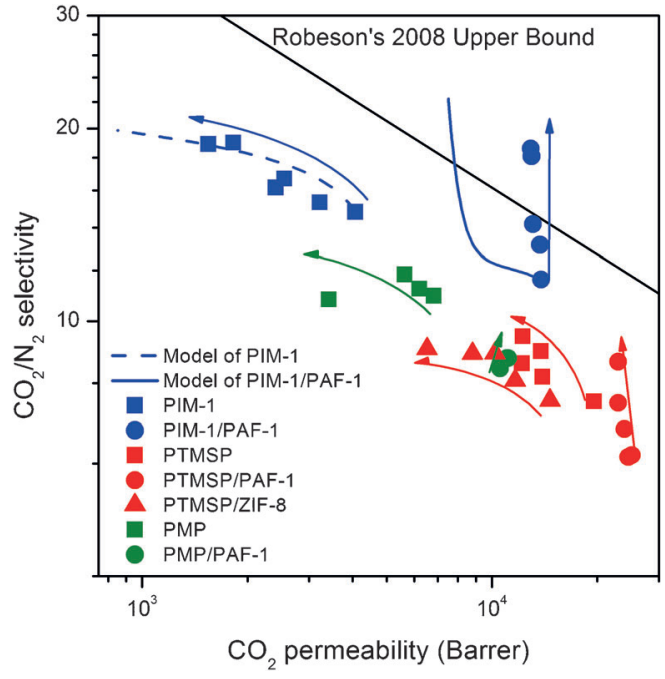

Figure 4. The single gas $\mathrm{CO}_{2}$ permeability and ideal $\mathrm{CO}_{2} / \mathrm{N}_{2}$ selectivity of PTMSP (red), PMP (green), and PIM-1 (blue) based nanocomposites are plotted on Robeson's Upper Bound. ${ }^{[5]}$ The squares represent pure super glassy polymer films, circles represent super glassy polymer/PAF-1 films, and triangles represent super glassy polymer/ metal-organic framework films. Our model accurately predicts the aging trends in different systems. Ultimately, PAF-1-based nanocomposites perform better over time without any $\mathrm{CO}_{2}$ permeability loss. The arrows provide a visual guide to show the relationship between $\mathrm{CO}_{2}$ permeability and selectivity over time (aging is tracked from the bottom of each arrow).

fore the maintenance of enhanced $\mathrm{CO}_{2}$ permeability in PIM1 is attributable to both the $1.2 \mathrm{~nm}$ pore offering fast flux pathways, and the enhanced $\mathrm{CO}_{2}$ solubility coefficients within the optimal $0.47 \mathrm{~nm}$ pore.

These results suggest the reconsideration and re-application of super glassy polymer membranes in commercial settings, following years of promise with seemingly irreconcilable aging challenges. In summary, formation of nanocomposites from super glassy polymers and a nanoporous framework particle PAF-1 leads to a remarkable cessation in polymer aging and the undesired consequent permeability decline. The effect is achieved by an intimate mixing of polymer chains within the porous PAF-1 matrix, with evidence of tethered bulky side-chains/chemical moieties of super glassy polymers within these pores. This approach can lead to dramatic enhancement across the entire family of rigid, microporous organic polymers, making these materials once again attractive for long-term industrial utilization, especially for PIM-1 membranes, as $\mathrm{CO}_{2} / \mathrm{N}_{2}$ selectivity is increased without the typical reduction of $\mathrm{CO}_{2}$ permeability.

Received: February 9, 2014

Published online: April 16, 2014

Keywords: aging - gas separation - membranes - polymers . porous materials

[1] J. M. S. Henis, M. K. Tripodi, Science 1983, 220, 11-17.

[2] R. W. Baker, Ind. Eng. Chem. Res. 2002, 41, 1393-1411. 


\section{Angewandte}

[3] D. L. Gin, R. D. Noble, Science 2011, 332, 674-676.

[4] A. W. Thornton, T. Hilder, A. J. Hill, J. M. Hill, J. Membr. Sci. 2009, 336, 101-108.

[5] L. M. Robeson, J. Membr. Sci. 2008, 320, 390-400.

[6] B. D. Freeman, Macromolecules 1999, 32, 375-380.

[7] J. Kurchan, Nature 2005, 433, 222-225.

[8] A. Peterlin, F. L. McCrackin, J. Polym. Sci. Polym. Phys. Ed. 1981, 19, 1003-1006; L. S. Kocherlakota, D. B. Knorr, Jr., L. Foster, R. M. Overney, Polymer 2012, 53, 2394-2401.

[9] M. Carta, R. Malpass-Evans, M. Croad, Y. Rogan, J. C. Jansen, P. Bernardo, F. Bazzarelli, N. B. McKeown, Science 2013, 339, $303-$ 307.

[10] T. Masuda, E. Isobe, T. Higashimura, K. Takada, J. Am. Chem. Soc. 1983, 105, 7473- 7474 .

[11] A. Morisato, I. Pinnau, J. Membr. Sci. 1996, 121, 243-250.

[12] S. Matteucci, V. A. Kusuma, D. Sanders, S. Swinnea, B. D. Freeman, J. Membr. Sci. 2008, 307, 196-217; S. Matteucci, V. A. Kusuma, S. D. Kelman, B. D. Freeman, Polymer 2008, 49, 1659 1675; D. Gomes, S. P. Nunes, K.-V. Peinemann, J. Membr. Sci. 2005, 246, 13-25.

[13] K. Nagai, S. Kanehashi, S. Tabei, T. Nakagawa, J. Membr. Sci. 2005, 251, 101 -110; I. Pinnau, C. G. Casillas, A. Morisato, B. D. Freeman, J. Polym. Sci. Part B 1996, 34, 2613-2621.

[14] E. Rangel Rangel, E. M. Maya, F. Sánchez, J. de Abajo, J. G. de La Campa, J. Membr. Sci. 2013, 447, 403-412.

[15] L. Shao, J. Samseth, M.-B. Hägg, Plasma Processes Polym. 2007, 4, $823-831$.

[16] F. Y. Li, Y. Xiao, T.-S. Chung, S. Kawi, Macromolecules 2012, 45, $1427-1437$.

[17] S. D. Kelman, B. W. Rowe, C. W. Bielawski, S. J. Pas, A. J. Hill, D. R. Paul, B. D. Freeman, J. Membr. Sci. 2008, 320, 123-134.

[18] P. M. Budd, E. S. Elabas, B. S. Ghanem, S. Makhseed, N. B. McKeown, K. J. Msayib, C. E. Tattershall, D. Wang, Adv. Mater.
2004, 16, 456-459; P. M. Budd, N. B. McKeown, D. Fritsch, Y. Yampolskii, V. Shantarovich, Membrane Gas Separation, Wiley, Hoboken, 2010, pp. 29-42.

[19] M. D. Guiver, Y. M. Lee, Science 2013, 339, 284-285.

[20] A. F. Bushell, P. M. Budd, M. P. Attfield, J. T. A. Jones, T. Hasell, A. I. Cooper, P. Bernardo, F. Bazzarelli, G. Clarizia, J. C. Jansen, Angew. Chem. 2013, 125, 1291-1294; Angew. Chem. Int. Ed. 2013, 52, 1253-1256.

[21] T. C. Merkel, H. Lin, X. Wei, R. Baker, J. Membr. Sci. 2010, 359, $126-139$.

[22] T. Ben, H. Ren, S. Ma, D. Cao, J. Lan, X. Jing, W. Wang, J. Xu, F. Deng, J. M. Simmons, S. Qiu, G. Zhu, Angew. Chem. 2009, 121, 9621-9624; Angew. Chem. Int. Ed. 2009, 48, 9457-9460.

[23] K. Konstas, J. W. Taylor, A. W. Thornton, C. M. Doherty, W. X. Lim, T. J. Bastow, D. F. Kennedy, C. D. Wood, B. J. Cox, J. M. Hill, A. J. Hill, M. R. Hill, Angew. Chem. 2012, 124, 6743-6746; Angew. Chem. Int. Ed. 2012, 51, 6639-6642.

[24] T. C. Merkel, Z. He, I. Pinnau, B. D. Freeman, P. Meakin, A. J. Hill, Macromolecules 2003, 36, 6844-6855.

[25] M. Woo, J. Choi, M. Tsapatsis, Microporous Mesoporous Mater. 2008, 110, 330-338.

[26] K. De Sitter, P. Winberg, J. D'Haen, C. Dotremont, R. Leysen, J. A. Martens, S. Mullens, F. H. J. Maurer, I. F. J. Vankelecom, J. Membr. Sci. 2006, 278, 83-91; P. Winberg, K. DeSitter, C. Dotremont, S. Mullens, I. F. J. Vankelecom, F. H. J. Maurer, Macromolecules 2005, 38, 3776-3782.

[27] A. J. Hill, S. J. Pas, T. J. Bastow, M. I. Burgar, K. Nagai, L. G. Toy, B. D. Freeman, J. Membr. Sci. 2004, 243, 37-44.

[28] Y. P. Yampol'skii, V. P. Shantorovich, F. P. Chernyakovskii, A. I. Kornilov, N. A. Plate, J. Appl. Polym. Sci. 1993, 47, 85-92.

[29] A. Morisato, H. C. Shen, S. S. Sankar, B. D. Freeman, I. Pinnau, C. G. Casillas, J. Polym. Sci. Part B 1996, 34, 2209-2222. 